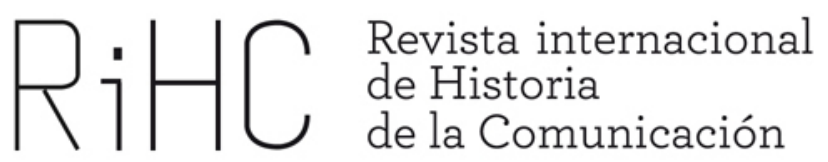

\title{
ANTENA 3 RADIO: NACIMIENTO Y PRIMER DESARROLLO DE UNA EMPRESA PERIODÍSTICA SINGULAR
}

DOI: http://dx.doi.org/10.12795/RiHC.2015.i04.08

\author{
Carlos Barrera \\ Universidad de Navarra \\ cbarrera@unav.es \\ Pilar Dobón Roux \\ Universidad de Navarra \\ mdobon@alumni.unav.es
}

Recibido: 3-5-2015

Aceptado: 16-6-2015

Resumen: La mayor novedad en el panorama de la radio española tras la muerte de Franco fue la aparición de Antena 3 Radio en 1982. El análisis de sus comienzos desde el punto de vista empresarial es relevante por varias razones: su intencionada radicación en las libertades de información y de empresa reconocidas por la Constitución de 1978; su origen en el declarado propósito de crear un canal privado de televisión; la presencia entre los socios de diversas empresas informativas; y el papel protagonista de conocidos periodistas y personajes con notoriedad pública. Con las 
ideas de libertad e independencia como estandarte, Antena 3 rompió el duopolio que de facto mantenían las cadenas Radio Nacional de España (pública) y SER (privada), y en apenas diez años se convirtió en la cadena con mayor audiencia en España. Junto a la vertiente empresarial, se describirá también en parte la periodística y la ideológicapolítica, de algún modo inseparables del proyecto. Se utilizarán para ello fuentes bibliográficas, hemerográficas, algunas orales y también del archivo de un director de periódico para un caso específico.

Palabras clave: Antena 3 Radio, transición, libertad de prensa, radio, televisión privada

Abstract: The launch of Antena 3 Radio in 1982 was the main event in the radio landscape in Spain after the death of Franco. An analysis of the beginnings, from the business perspective, is relevant because of some characteristics: the promoters' insistence on the freedom of the press and free enterprise, both recognized in the Constitution of 1978; their primary intention of launching a commercial television channel; the presence of various news media companies as shareholders; and the outstanding role played by well-known journalists and other renowned persons in the public sphere. Waving the flags of freedom and independence as driving ideas, Antena 3 broke the de-facto duopoly held by RNE (public) and SER (commercial), and would become the network with the largest audience in only ten years. To achieve a more comprehensive overview, the journalistic project of Antena 3 and its ideological principles will also be described. The sources used for this article include books, journals, daily newspapers of the time, some oral testimonies and one archive of a newspaper editor to deal with a specific case.

Keywords: Antena 3 Radio, transition to democracy, freedom of the press, radio, commercial television 


\section{Introducción}

\subsection{Interés del tema y objetivos}

La transición española a la democracia entre los años 1975 y 1982 conoció importantes novedades en el mundo de los medios de comunicación desde el punto de vista de las libertades de expresión y de empresa. Ambas fueron reconocidas en la Constitución de 1978 a través de los artículos 20 y 38 respectivamente.

No fue homogéneo, sin embargo, el desarrollo de dichas libertades en los distintos medios: prensa, radio, televisión y agencias informativas. En el terreno empresarial confluyeron los intereses de quienes eran ya empresarios de prensa y de quienes comenzaron a serlo a partir de la muerte de Franco. La expansión estratégica y comercial hacia la radio y la televisión, hasta entonces casi patrimonios exclusivos del Estado (a excepción del caso de la cadena SER y otras pequeñas emisoras), provocó un lógico interés de distintos actores por estar presentes en estos nuevos medios que tenían generalmente mayor penetración, audiencia, atracción publicitaria y, por lo tanto, influencia; es decir, podían convertirse en rentables negocios que incidieran además en la configuración de la opinión pública.

Nadie quiso quedarse atrás en esta carrera por situarse en posiciones de privilegio en el nuevo panorama mediático que se abría con el reconocimiento de las libertades públicas, y en particular la de expresión recogida en el mencionado artículo 20 , esto es, el derecho "a comunicar o recibir libremente información veraz por cualquier medio de difusión". Enseguida comenzaron así a surgir peticiones, dirigidas al gobierno de la nación, de licencias para constituir sociedades privadas con el fin de explotar la televisión. Como esta no llegó a cuajar inmediatamente por distintas razones (Barrera 1995: 224-229), los intereses de las empresas periodísticas viraron de forma posibilista hacia la radio, donde entre 1981 y 1982 iban a concederse un total de 300 nuevas licencias de frecuencia modulada (FM). La radio apareció para algunos como el camino adecuado y provisional de preparación para la futura televisión privada, aunque también se erigió como medio con interés en sí mismo. Muestra de ello fue que su audiencia creció de 6,8 millones de oyentes en 1976 a los 16,3 millones de 1982, según datos del Estudio General de Medios (Franquet y Martí, 1989: 38).

El caso de Antena 3 resulta paradigmático porque reúne la mayor parte de los ingredientes antes apuntados. Quiso ser una televisión pero las dificultades políticas de los crecientemente débiles gobiernos de UCD y una sentencia dilatoria del Tribunal Constitucional hicieron recular a sus promotores y centrarse en el lanzamiento de una cadena de radio en tanto no fuera posible la televisión. Es lo que Balsebre (2002: 483) ha denominado "dimension instrumental" del negocio de la radio "frente al futuro negocio televisivo". Así comenzó sus emisiones Antena 3 Radio en la primavera de 1982. Su accionariado, aunque capitaneado mayoritariamente por el grupo Godó, 
estaba compuesto por diversas empresas periodísticas, además de algunos conocidos profesionales en la vida pública.

El estudio de este caso desde la vertiente empresarial nos introduce asimismo en el mundo de la formación de los primeros grupos modernos de comunicación en España. Al aluvión de solicitudes recibidas para los concursos de FM respondieron los gobiernos centristas con el favorecimiento en sus concesiones a las empresas periodísticas ya existentes tanto a nivel nacional como regional y local, en un reparto que no permitía aparentemente la constitución de nuevas cadenas.

Junto con la vertiente empresarial, que es la principal en este estudio, se describe también en parte la profesional periodística y la ideológica-política, de algún modo inseparables del proyecto empresarial forjado por los accionistas principales de la sociedad. Son objetivos de este artículo analizar los aspectos novedosos del proyecto empresarial y periodístico de Antena 3 y destacar, por tanto, su singularidad en el panorama audiovisual de la época y sus aportaciones principales en el mundo de la radio. Indirectamente, y teniendo en cuenta sus orígenes, también interesa conocer el posible trato de favor que pudieron tener los empresarios de Antena 3 por parte del gobierno y en qué grado, caso de existir, favoreció su desarrollo.

\subsection{Metodología}

A pesar de ser posiblemente el nuevo medio de comunicación más exitoso en la España de los años ochenta, no se ha escrito aún una historia ordenada, completa e integral de Antena 3 Radio en sus diferentes facetas o niveles: como proyecto periodístico, como empresa y como medio influyente en la opinión pública de su tiempo. Se han publicado historias generalistas del medio pero contienen algunas limitaciones: cronológicas en los casos de Balsebre (2002) y Faus (2007), pues apenas llegan hasta 1985 y 1977 respectivamente; y de género en el caso de Lorenzo Díaz (1992), por su carácter asistemático y de divulgación más que propiamente científico. Otras de carácter más general se refieren a un contexto más amplio como las de Bustamante (2013), desde un enfoque más propio de la economía política y más centrado en la radiotelevisión pública, y Fernández y Santana (2000) desde la perspectiva de las políticas de información.

En este artículo se ofrece una exploración de sus orígenes y primer desarrollo, centrada sobre todo en el aspecto empresarial como elemento motor de la idea originaria. Por eso, desde un punto de vista cronológico, y dados también los límites de un artículo como este, se abarca el período comprendido entre 1979, cuando empieza a gestarse el proyecto, y 1984, fecha en que se produce la compra de la cadena Radio 80 por parte de Antena 3 y una notable expansión de esta última como consecuencia. 
Radio 80 había sido formada también a raíz de los concursos públicos de 1981 y 1982, y guardaba algunas similitudes de planteamiento.

Se han utilizado, para todo ello, fuentes bibliográficas acerca de la historia de la radio y de la televisión de la época, junto con las de tipo hemerográfico. Estas últimas se pueden dividir en dos: las encontradas en periódicos de referencia, ideológicamente variados y de mayor circulación como La Vanguardia, $A B C$ y El País, y las halladas tras una labor de rastreo en publicaciones especializadas de publicidad y marketing como IP-Mark y Anuncios. Mientras La Vanguardia y $A B C$ se hicieron eco habitual de las noticias acerca de la gestación y desarrollo de Antena 3, dado que sus empresas propietarias eran socios de referencia de la nueva cadena, El País mostró una línea más analítica y en ocasiones crítica. El interés del diario de Prisa por tratar en sus páginas los temas de periodismo y comunicación, y su condición de diario nacional líder en difusión, son razones añadidas para su consulta como fuente. El País, La Vanguardia y $A B C$ presentan además la ventaja añadida de la mayor facilidad de búsquedas en sus hemerotecas digitales. Por su parte, IP-Mark y Anuncios representan los intereses supuestamente neutrales de publicaciones profesionales pertenecientes al mundo de la publicidad y del marketing.

Asimismo, se ha podido contar, para contrastar informaciones obtenidas de estas fuentes, con tetimonios orales de algunos protagonistas de aquella historia. Del mismo modo, gracias al archivo personal del ex director de La Vanguardia Horacio Sáenz Guerrero, ya manejado anteriormente por uno de los autores (Nogué y Barrera, 2006), se ha podido añadir algún elemento de interés a la narración. En definitiva, hemos reunidos informaciones que se encontraban sumamente dispersas para darles un sentido y explicar la originalidad de una empresa llamada a tener un protagonismo destacado en la historia del sector audiovisual en España.

\section{Restricciones y posibilidades del marco jurídico-legal}

La apertura liberalizadora en el sector de la radiodifusión fue gradual, incompleta y discrecional: gradual por cuanto requirió de diversas decisiones políticas tomadas a lo largo de los años de la transición; incompleta dado que, desde el punto de vista técnico, el número de licencias concedidas podía haber sido aún mayor; y discrecional porque los gobiernos centristas fueron quienes decidieron, en última instancia, quiénes y cómo iban a resultar favorecidos en el reparto. A menudo se les criticó su preferencia por gobernar, en este y en otros asuntos, mediante decretos que no pasaban por la discusión parlamentaria. La gran excepción fue el Estatuto de la Radio y 
de la Televisión de 1980, consensuado con los socialistas como principal partido de la oposición (Fernández y Santana, 2000: 100-108; Palacio, 2012: 218-223; Bustamante, 2013: 83-93).

Fue precisamente una norma de rango menor, en concreto una orden ministerial, la que en octubre de 1977 permitió a las emisoras ofrecer información política, hasta entonces coto de Radio Nacional de España (RNE), con la que todas las emisoras debían conectar para emitir los "diarios hablados" del mediodía y de la noche. La única cadena con capacidad profesional e infraestructura técnica para llevarlos a buen término era la SER, que así pudo competir con RNE también en el terreno informativo. Pero, en definitiva, se abría el panorama a cualesquiera otras cadenas que se configuraran en el futuro. Con el fin del monopolio informativo de la radio pública se abrió lógicamente el apetito de las empresas periodísticas privadas por competir en un terreno, el de la información, que consideraban también legítimamente suyo.

La Constitución de 1978 vino a confirmar, al más alto nivel jurídico, la libertad de expresión a través de cualquier medio. Desde un punto de vista práctico, originó como cabía esperar- un creciente número de peticiones para la autorización, sobre todo, de canales privados de televisión, que era el negocio más apetecido por las principales empresas periodísticas españolas. Los silencios administrativos ante tales peticiones motivaron que una de ellas, Antena 3, emprendiera acciones legales para que se les reconociera ese derecho (Antena 3: 1982).

Esta sociedad fue formada en 1979 y contaba con la participación de conocidos grupos empresariales como Godó, Zeta, Prensa Española y Europa Press, y la dirección estratégica del periodista Manuel Martín Ferrand y los hermanos juristas Manuel y Rafael Jiménez de Parga. Llevaron su causa hasta el Tribunal Constitucional al interponer un recurso de amparo por serle denegada la autorización para lanzar un canal de televisión privada. En anuncios insertados en la prensa de la época quisieron acentuar su papel de punta de lanza en esta lucha cuando decían:

Porque para defender el derecho a informar, no basta con hablar y pedir que le oigan; es necesario actuar. Y esto es lo que está haciendo Antena 3. Hay varios grupos españoles que están hablando de nuevos canales de televisión, pero sólo Antena 3 ha acudido a la Constitución para defender el derecho a la libertad de información y a la libertad de empresa (ABC, 6-4-1982, p. 60).

La sentencia del Constitucional, de 31 de marzo de 1982, entre salomónica y dilatoria, significaba que se reconocía teóricamente el derecho pero que la regulación de las televisiones privadas se remitía a una decisión política del gobierno de turno mediante una ley orgánica (González Navarro, 1982: 289). De la división interna, también en este tema, en la UCD gobernante no cabía esperar su pronta resolución. Además, el consensuado Estatuto de la Radio y de la Televisión de 1980 supuso un jarro de agua 
fría para quienes albergaban alguna esperanza de que recogiera las aspiraciones de los grupos interesados en la televisión privada. La concluyente definición de ambos medios como "servicios públicos esenciales cuya titularidad corresponde al Estado", unida a la ausencia de cualquier mención a la gestión privada, eran signos inequívocos de la falta de voluntad política para autorizarla.

La paralela apertura acometida en el sector de la radiodifusión por los gobiernos centristas de Adolfo Suárez y Leopoldo Calvo-Sotelo acaparó entonces el interés de los operadores privados de televisión, que se trasladó -al menos de forma transitoria- a las anunciadas nuevas concesiones de emisoras de radio en frecuencia modulada. El Plan Técnico de Radiodifusión Sonora de 1978 y el subsiguiente Plan Transitorio de FM de 1979 prepararon el camino para la convocatoria de sendos concursos públicos en 1980 y 1981, por los que se licitarían un total de 300 nuevas emisoras en dos fases (García Llovet, 1991: 257-267). Del interés despertado por el primer anuncio da fe el número de unas 2.000 solicitudes presentadas en 1980 . Una cantidad similar se presentó para la segunda convocatoria. Hasta entonces, la FM había producido cambios importantes en Estados Unidos y en Europa, pero apenas en España debido a la falta de fabricación de receptores que la incluyeran (Faus, 2007: 871-873).

\section{Antena 3 como empresa}

En 1989 Manuel Martín Ferrand (1991: 22) dijo en público: “Antena 3 es un concepto, más que una empresa, que nace en 1979 (...) Recién aprobada la Constitución de 1978 -continuó diciendo-, nos reunimos en Ginebra los profesores Manuel y Rafael Jiménez de Parga; el primero en su condición de experto constitucionalista; el segundo en calidad de mercantilista y yo en mi condición de amigo de los dos". Estrictamente hablando, la empresa se conformó en septiembre de 1980.

Nació, pues, al calor de los nuevos derechos y libertades públicas reconocidos por la Constitución, y con la intención inicial de hacer la primera televisión privada de ámbito nacional en España. En un artículo publicado en 1982, Rafael Jiménez de Parga unía los conceptos de democracia e iniciativa privada en estos términos: "Estamos, por consiguiente, ante la ineludible tarea de fortalecer el sistema democrático y constitucional mediante la liberalización de las estructuras y el impulso de la iniciativa privada". Y señalaba que, en el ámbito concreto de la radio, "el diseño de un mercado más libre y plural (...) pasaba por la ruptura de un cierto statu quo existente al amparo de una ausencia de disposiciones que abrieran a otras opciones este sector" (Jiménez de Parga, 1982: 13). Las primeras concesiones de 1981 comenzaron a abrir ese camino. 
Para romper el muro de incomprensión que entre la mayoría de la clase política de distinto signo se levantaba contra esa idea, los emprendedores de Antena 3 organizaron unos 1.500 actos públicos por toda España con el mensaje clave: "La libertad también se llama televisión" (Martín Ferrand, 1991: 22). Sin embargo, este propósito inicial hubo de reconducirse, de forma pragmática y posibilista, hacia el mundo de la radio, a la par que la empresa emprendía la lucha jurídica en el Constitucional.

De hecho, al principio la sociedad creada llevaba solamente el nombre de "Antena 3 S.A.", sin referencia alguna a la radio. Cuenta Manuel Jiménez de Parga en sus memorias que, tras su fugaz paso como ministro en el primer gobierno democrático de Suárez entre 1977 y 1978, Manuel Martín Ferrand -con quien le unía una ya larga relación- le insistió en el asunto de romper el monopolio oficial de la televisión, del que ya habían tratado en anteriores ocasiones. Entonces le citó en una comida junto a los dos grandes empresarios de prensa catalanes: Antonio Asensio y Javier Godó. De ahí salió la necesidad de contar también con accionistas de Madrid, que fueron a la sazón José Mario Armero (Europa Press) y Guillermo Luca de Tena $(A B C)$. La presidencia de la sociedad recayó en su hermano Rafael, "en una solución de compromiso entre los varios grupos financieros" (Jiménez de Parga, 2008: 320-321).

Las empresas periodísticas que formaron el núcleo duro del proyecto fueron las cuatro grandes ya mencionadas: TISA-La Vanguardia, Prensa Española-ABC, Zeta y la agencia de noticias Europa Press. Los nombres de sus principales directivos o ejecutivos poseían una fuerza importante en el panorama mediático de la época y representaban además a los dos principales mercados: Madrid y Barcelona. En un anuncio que acompañaba la campaña pública en pro de conseguir la anhelada televisión privada se utilizaba este argumento como demostración de poderío: "Somos el grupo de información más potente del país, puesto de acuerdo para hacer televisión a fondo (...) Somos hoy semanalmente 4 millones de ejemplares, cientos de noticias, toneladas de información responsable" (La Vanguardia, 15-11-1981, p. 21).

Martín Ferrand destacaba, ya en 1983, la novedad que suponía en España integrar en un mismo proyecto a actores tan diversos e incluso rivales, como era el caso de los grupos Godó y Zeta en Barcelona: “Por primera vez en la historia de nuestro periodismo, diferentes empresas periodísticas se embarcan en un propósito común de cooperación, realmente nuevo, en este país tan individualista 'per se' (Molinero: "Antena-3: cumpleaños feliz", La Vanguardia, 28-5-1983, p. 78). Una información aparecida en El País, apenas un mes después de la puesta en marcha de Antena 3 Radio, describía a esta -no sin fundamento- como "propiedad de un grupo de profesionales del mundo de la información, del derecho y del empresariado" (Beaumont: "Las nuevas emisoras abandonan la fórmula musical de las FM", El País, 27-5-1982). 
Debido a su ambición, el proyecto acaparó enseguida el interés informativo de la prensa, que lo situó habitualmente como uno de los más sólidos, primero para la explotación de la televisión y, una vez que el camino hacia esta se cerró -al menos temporalmente-, también para la radiodifusión. En vísperas del inicio de sus emisiones, El País calificaba a Antena 3 como "la más potente del dial", y señalaba que "ha ido atrayendo a periódicos, sociedades y particulares que no formaban parte de Antena 3", entre los que mencionaba a los periodistas Basilio Rogado y Enrique Barrueco y diarios como La Voz de Galicia, Diario de Cádiz, Diario de León y el mallorquín Última Hora (Pérez Ornia: "Nacen las nuevas emisoras de FM", El País, 2-51982).

Desde el punto de vista profesional periodístico el liderazgo y la dirección del proyecto correspondían claramente a Martín Ferrand, pero su actividad no se limitó únicamente a este aspecto ya que fue igualmente el motor de la incorporación de otras empresas periodísticas a la sociedad. Recorrió España para "vender" la idea a muchas de ellas y hacer, al mismo tiempo, una labor de creación de opinión pública favorable a la pronta implantación de la televisión privada. Su estrecha relación con Antonio Asensio facilitó la entrada del grupo Zeta (Miró, 1997: 35). Los Godó fueron invitados a participar por su reconocida influencia en el ámbito de la opinión pública escrita y sus conocidos intentos de contar con más influencia en la capital de España (Nogué y Barrera, 2006: 298-309). Hacía falta también, de cara al éxito de la operación, una buena presencia en Madrid, y de ahí la entrada de $A B C$ y Europa Press. Al final acabaron integrándose, según manifestó el propio Martín Ferrand, un total de veintitrés empresas periodísticas.

"Siempre entendimos -rememoraba en 1989- que una cierta especialización del capital es el primer punto de coherencia en una empresa periodística". Esa fue la razón por la que convocaron "a los viejos periódicos españoles más avezados en la guerra de la información y en la batalla de la libertad" (Martín Ferrand, 1991: 23). Así nació la sociedad "Antena 3 de Radio, S.A.", inscrita en el registro mercantil el 9 de octubre de 1981, es decir, apenas dos meses y medio antes de las primeras concesiones de FM. Sus 50 millones de pesetas de capital inicial y la composición de éste eran toda una declaración de intenciones de que se iba en serio. A pesar de la fragmentación del accionariado, el peso principal y mayoritario del capital lo llevó desde los inicios TISALa Vanguardia, que apareció así como la cara empresarial más visible de la operación. La dirección periodística y comercial, así como la relación con la propiedad, recayó en las expertas manos de Martín Ferrand, periodista con una larga trayectoria en prensa, radio y televisión: cadena SER, TVE, Diario de Barcelona, Nuevo Diario, etc. (Díaz, 1992: 442-443) 
A modo de resumen programático, Rafael Jiménez de Parga manifestó públicamente a finales de 1982, como presidente del consejo de administración, las ventajas de esa fórmula empresarial tan poco usual:

Antena 3 se constituye sobre un pluralismo interno que no le resta coherencia, sino que potencia su quehacer. Aparece como el punto convergente de un conjunto de medios de comunicación aglutinados por el denominador común del respeto del orden constitucional, por el ejercicio diario de la tolerancia y el respeto a las libertades públicas, y por la firme creencia y práctica de la libertad de pensamiento que, traducida al campo de la empresa, es libertad de concurrencia como fundamento de una sociedad libre ("Antena 3 inició sus emisiones en Barcelona", El País, 12-12-1982).

\section{4 ¿Un impulso político detrás de las concesiones?}

Estas declaraciones del presidente de Antena 3 guardan cierta relación con los principios ideológico-políticos por los que se guió la cadena, y que se resumían en seis puntos:

1‥- El pleno respeto a la Constitución Española de 1978 y, de manera especial, la defensa de la soberanía del pueblo y del desarrollo de los derechos humanos.

20.- La defensa de la unidad política de España y de sus diversidades lingüísticas y culturales, dentro de un sistema de comunidades autónomas.

3‥- La defensa de la monarquía parlamentaria como garantía de las libertades públicas y del pluralismo político.

4‥- La defensa de la economía de mercado, de la libre iniciativa económica y de la competitividad del sistema.

5․- El progreso social, la reforma de las estructuras de la sociedad y la obtención de unas condiciones básicas de igualdad de oportunidades.

6‥- El derecho a una información veraz, libre y plural (“Código ideológico de Antena 3", IP-Mark, № 225, 10-1982, p. 49).

Dichos principios fueron leídos durante la primera emisión del 4 de mayo de 1982, y comunicados al personal de la cadena por el director general Martín Ferrand (La Vanguardia, 5-5-1982, p. 13). Dentro de su generalidad, pero muy en sintonía con los 
pilares del texto constitucional, destacaban sobre todo dos aspectos: la libertad de empresa y la de información; los mismos que habían constituido su bandera para reivindicar la creación de un canal privado de televisión. El propio rey Juan Carlos, que por la mañana había recibido al consejo de administración de Antena 3, leyó un mensaje que recalcaba, desde su plano institucional, estas mismas ideas: "La información libre, la información veraz, nos proporciona bienestar. Y la libertad, como se dijo con expresión clásica, es la salud del alma". De ahí que terminara diciendo: "Al servicio de esta España de hombres y de mujeres bien informados, de ciudadanos libres, me es muy grato saludar a todos cordialmente al inaugurar la cadena de emisoras de Antena 3" (La Vanguardia, 5-5-1982, p. 13; ABC, 5-5-1982, p. 7).

Durante el proceso que condujo a la creación y primera expansión de la nueva cadena, y de acuerdo también con algunas versiones de periodistas y de protagonistas de la época, se albergaron sospechas de cierto trato de favor hacia ella por parte de los gobiernos centristas de la época: de Adolfo Suárez primero y de Leopoldo Calvo-Sotelo después. Un reportaje de El País hablaba del que llamaba "grupo Suárez": un total de diez emisoras pertenecientes a tres empresas concesionarias distintas (Capyrsa, Proal y Ebalsa), que se incorporaron a Antena 3. Señalaba además a los hombres que, según su versión, lo hicieron posible: Aurelio Delgado, cuñado del ex presidente Suárez; Josep Meliá, que había sido secretario de Estado para la Información también con Suárez; y el abogado Juan Belda. Todos ellos trabajaban entonces en el despacho de abogados del ex presidente del gobierno (Pérez Ornia, "Nacen las nuevas emisoras de FM", en El País, 2-5-1982; Anuncios, no 172, 24 a 30-9-1984, p. 10)

En septiembre de 1984 la sociedad Capyrsa vendió el 23\% de acciones que tenía en Antena 3. La revista Anuncios decía que en ella tenía una participación mayoritaria Adolfo Suárez. Martín Ferrand, que confirmó esa operación de venta, la calificó como normal, "una de tantas que se producen en el mundo mercantil", y decía no constarle vinculación alguna del ex presidente con dicha empresa (Anuncios, n 172, 24 a 30-91984, p. 10).

Apuntaba El País además al abogado y economista Javier Gimeno, director general adjunto de Antena 3, como el hombre vinculado a esta operación. Según declaró al autor del reportaje, Meliá dijo no ser accionista de ninguna de esas empresas: "Nosotros -aclaró- lo único que hicimos fue juntar amigos y clientes que luego se asociaron a Antena 3. Jimeno [sic] es amigo nuestro y estaba vinculado al despacho de Juan Belda". Tratando de quitarle hierro al asunto, el director general Manuel Martín Ferrand le dio la vuelta al argumento: "Es una gran entelequia eso de saber quiénes están detrás de los medios. Nuestras emisoras integran a veintitrés empresas periodísticas. Lo importante son los que están delante" (Anuncios, no 172, 24 a 30-91984, p. 10). Intentando contradecir de algún modo a Martín Ferrand, el autor del reportaje explicaba a continuación que dos de los principales cargos directivos de 
Antena 3 Radio procedían también de ámbitos ministeriales: José Luis Orosa, director de programación, y José Cavero, director de informativos, habían trabajado en Hacienda y Justicia respectivamente como jefe de prensa el primero y jefe del gabinete técnico el segundo.

Luis Herrero era uno de los jóvenes periodistas que se incorporaron a la primera redacción de la cadena. Resulta conocida la relación personal que desde su infancia tuvo con la familia Suárez y su entorno (Herrero, 2007). No hace muchos años escribió que, dentro del accionariado de Antena 3, existía lo que en el argot interno llamaban "el grupo de los azules", en referencia a aquellos que dependían de alguna manera de Aurelio Delgado. De hecho, relata que su primera entrevista con Martín Ferrand para entrar en la redacción la hizo porque "mandó a verle el testaferro del principal accionista de la cadena de radio". Y aclara: "Éste era UCD y aquél Aurelio Delgado". Algo más adelante también se atreve a calificar a Javier Gimeno como "el director general adjunto impuesto por los azules" (Herrero, 2008: 153-158). Sobre el origen de la denominación de "los azules" que quedó acuñada, defiende una versión distinta la viuda de Martín Ferrand, en entrevista a los autores. Mantiene que se debió a que los papeles de su incorporación al accionariado los firmaron con bolígrafos azules, y de ahí les vino el nombre, no tanto por su procedencia política (González de Haro, 2015).

Estos supuestos movimientos en la sombra hay que confrontarlos, no obstante, con la realidad del número ciertamente muy limitado de concesiones directas que consiguió Antena 3, a todas luces insuficientes para poner en marcha una cadena de ámbito nacional. Martín Ferrand dijo que, estrictamente hablando, sólo recibió una en Puertollano, y que las demás se fueron consiguiendo "por negociaciones, adquisiciones, pactos, entendimientos y magias diversas, demostrando una vez más que no se le pueden poner puertas al campo, y que por grande y represor que sea el instinto del gobernante, más amplio debe ser el talento burlador de los que acometen alguna aventura en el terreno de las libertades" (Martín Ferrand, 1991: 24-25). Aunque en estas palabras no indica el sujeto que las llevó a cabo, por testimonio directo y privilegiado se sabe que fue el propio director general quien "fue visitando y convenciendo uno a uno a concesionarios de liciencias de emisoras por toda España para que se integraran en Antena 3" (González de Haro, 2015).

A finales de los años ochenta, Rosa Franquet escribió que Antena 3 "fue uno de los más beneficiados en el reparto de emisoras de FM", si bien no proporcionaba sino conjeturas cuando apuntaba que "una razón plausible puede ser la vinculación de la sociedad con [José Miguel] Bravo de Laguna, funcionario del Registro de empresas y emisoras de la Dirección general de Medios de Comunicación Social". Basada en este posible enlace, aventuraba que Antena 3 contó con "un asesoramiento directo" que le permitió "crear sociedades intermedias con la finalidad de acaparar el mayor número de licencias" entre propias, asociadas y participadas. La posterior adquisición, en 1984, 
de la mayoría de las estaciones de Radio 80, cadena surgida también de aquellas concesiones, fue vista por la autora como un proceso que "podría pensarse que estaba planificado de antemano" (Franquet, 1988: 90-91). Luis Ángel de la Viuda (2015), en entrevista con los autores, lo ha negado, y achacó la venta de Radio 80 a causas exclusivamente económicas.

El reparto de las concesiones fue, ciertamente, un proceso falto de transparencia por parte de los gobiernos de la UCD. Como señalan Fernández y Santana (2000: 160), "el Gobierno actuó discrecionalmente a la hora de realizar las concesiones". Las 300 emisoras que se distribuirían en dos fases, de 120 primero y 180 después, recayeron principalmente en empresas periodísticas o radiofónicas. Lo había anunciado previamente el secretario de Estado para la Información, Ignacio Aguirre, argumentando que se hacía como reconocimiento a su labor profesional en el mundo de los medios. Eso aumentaba las posibilidades de Antena 3, dado que en su accionariado se daban cita precisamente ese tipo de empresas.

Como Aguirre no facilitó la lista de adjudicatarios, que solo se dieron a conocer directamente a los agraciados, aumentaron las acusaciones de secretismo y favoritismo, como hizo la oficina de prensa del PSOE. En un comunicado público denunció que las concesiones habían sido "una burla a la libertad de expresión", dado que una buena parte de ellas fueron a parar "a grupos cuyas conexiones ideológicas y políticas con el partido que soporta [sic] al Gobierno son claras y manifiestas" (Fernández y Santana, 2000: 161). El gobierno reaccionó con una nota en la que justificaba sus criterios: el favorecimiento a los medios informativos, "a los que se brinda la oportunidad de convertirse en multimedio. Entre más de 2.000 solicitudes se ha elegido a medios con solvencia para no propiciar a los aventureros de estos medios" (El País, 21-1-1982). En el fondo, la dispersión de las adjudicaciones fue también interpretada, especialmente por los afectados, como un intento de no fomentar la creación de nuevos grupos o el fortalecimiento excesivo de otros ya existentes.

En esa primera fase del concurso no se concedieron licencias de emisión en Cataluña y el País Vasco, dado que existía un conflicto de competencias entre el Estado y los respectivos gobiernos autonómicos, que habían reclamado para sí esas competencias. Finalmente, el Tribunal Constitucional se posicionó a favor de estos últimos en sendas sentencias de mayo y julio de 1982, dictaminando que al Estado sólo correspondían las facultades de inspección pero no las competencias ejecutivas y el desarrollo normativo. La tensión entre los licitantes por incorporarse a este nuevo medio chocó a veces con esta cuestión "autonómica", provocando reacciones de irritación. Tal fue el caso, por ejemplo, del principal accionista de Antena 3, el grupo Godó.

En efecto, el día 30 de diciembre de 1981, el delegado de La Vanguardia en Madrid, el periodista José Tarín, enviaba al gerente-editor del grupo, Javier Godó, una nota bajo el título "Muy confidencial", donde detallaba los entresijos de la decisión de no otorgar 
a La Vanguardia una de las 120 primeras concesiones. Según esa información, la petición del diario catalán fue desestimada "arguyendo que parecía poco prudente la concesión de una Emisora propiedad de un diario de Barcelona en Madrid, cuando se ignoraba lo que pasaría en Cataluña, donde algunos diarios de Madrid -concretamente El País y Diario 16- tienen solicitadas Emisoras en Barcelona". Godó pasó esta nota al director del diario, Horacio Sáenz Guerrero, y le comentó que formaba parte de "estos continuos agravios que nos han hecho", y le sugería -como había propuesto Tarínpublicar un editorial sobre el tema ("Nota para Javier Godó", 30-12-1981, y Carta de Javier Godó a Horacio Sáenz Guerrero, 31-12-1981, cit. por Nogué y Barrera, 2006: 322).

Al día siguiente, bajo el título "Una marginación injusta", La Vanguardia calificaba como muestra de "desdén" y "en definitiva, de un centralismo activo y militante", la decisión adoptada por el Gobierno de no tomar siquiera en consideración las solicitudes de empresas catalanas "con antigua y sólida implantación en Madrid que solicitaron una emisora por la capital" ("Una marginación injusta”, La Vanguardia, 1 y 2-1-1982, p. 7). Casi un año después, el gobierno catalán concedió a La Vanguardia una de las licencias de FM, y otra también al diario del mismo grupo El Mundo Deportivo (La Vanguardia, 17-12-1982). También Antonio Asensio, igualmente accionista de Antena 3, recibió otra.

\section{Estrategia de crecimiento y compra de Radio 80}

Dado el limitado número de concesiones conseguidas por sus socios fundadores, los planes de crecimiento de Antena 3 para alcanzar la cobertura nacional pasaron por la integración, asociación o afiliación de distintas emisoras a las que se habían otorgado licencias de emisión. Los cambios de titularidad fueron moneda común entonces, y los grupos más interesados en ellas fueron las cadenas de radio ya existentes como la SER, la COPE y la Rueda de Emisoras Rato, o las nuevas cadenas más pujantes salidas de esos concursos como Antena 3 y Radio 80 . Los acuerdos podían revestir distinta naturaleza, desde la colaboración y la asociación hasta la transferencia de la licencia de explotación.

Antena 3 fue, a este respecto, la más agresiva por cuanto su rentabilidad, en términos de audiencia y publicidad, dependía del éxito de esa estrategia de expansión geográfica por toda España. En la primavera de 1983, un año después de sus comienzos con 5 emisoras, tenía ya 33 funcionando en su red y se planteaba llegar a 54 en los siguientes doce meses. En un anuncio de autopromoción de la época se 
jactaba de ello y de otros logros adyacentes como haber creado 400 puestos de trabajo, facturar más de mil millones de publicidad, atraer a seis mil anunciantes locales y convertirse en la cadena "totalmente privada" con más audiencia en España ( $A B C$, 6-4-1982, p. 60). Para arrogarse tal título jugaba lógicamente con el hecho de que el Estado, por una normativa del franquismo, poseía el $25 \%$ de la SER y otras emisoras privadas, y una proporción algo menor de la COPE (Faus, 2007: 892-895). Como recordó años más tarde Martín Ferrand, "el empuje y la capacidad de creación de aquellos primeros pobladores de Antena 3, originó un 'récord' del Guiness, la fundación y puesta en marcha de una emisora cada diez días", con todo lo que ello conllevaba de tramitaciones administrativas en cada localidad, amén de los inevitables esfuerzos tecnológicos, profesionales y económicos (Martín Ferrand, 1991: 24).

En tiempos tan tempranos como el mes de agosto de 1982, cuando aún eran sólo once las emisoras de Antena 3, El País publicaba una noticia sobre la nueva cadena con un titular que irradiaba optimismo: "Los directivos de Antena 3 se muestran eufóricos por la marcha de la cadena". Martín Ferrand daba cifras concretas: "Madrid, en agosto, ha alcanzado una facturación de cerca de diez millones en publicidad; Almería, 2.000.000 de pesetas, y Sevilla, 500.000 pesetas menos". Mencionaba también que un estudio de audiencia, "esperanzador para nosotros", daba a Antena 3 el liderazgo en Madrid "durante ocho horas diarias" (El País, 30-8-1982). La razón era la presencia de la máxima figura de la radio deportiva española, José María García -que había dejado la SER a finales de 1981-, a partir de las doce de la noche.

Los buenos resultados cosechados y las inversiones necesarias para el crecimiento exigieron una ampliación de capital de 200 millones de pesetas en septiembre de 1982. Quedaba de esta manera duplicado respecto del inicial. A pesar de los rumores existentes acerca de que el grupo Zeta podía no acudir a dicha ampliación, finalmente también la suscribió. No obstante, un año más tarde acabaría por desprenderse de sus acciones en Antena 3, fortaleciendo la posición de predominio del grupo Godó, que fue el comprador.

Otro hito importante en el desarrollo de la cadena fue la inauguración de la emisora de Antena 3 en Barcelona, importante mercado publicitario, justo después de que la Generalitat concediera una de las licencias a La Vanguardia. Precisamente con ocasión de la puesta en marcha de esta emisora, el director general de Antena 3 Radio volvió a dar algunas cifras de facturación publicitaria: unos 450 millones de pesetas entre mayo y diciembre de 1982. Quería con ello acallar los rumores acerca de supuestas dificultades financieras del grupo: "Desde que salimos a la calle -dijo- hace casi diez meses no han cesado estos rumores, interesados, a los que nunca hemos hecho caso" (El País, 17-2-1983). Uno de ellos, interesado y que se demostró infundado, partió de Cambio 16: no hay que olvidar que el Grupo 16 era un rival radiofónico y televisivo (EI 
País, 29-3-1983), al igual que el propio El País que lanzaba ese mismo año Radio El País.

Posibles fundamentos de estas informaciones eran los cálculos de las inversiones requeridas para poner en marcha una cadena de tal magnitud como Antena 3. El País lo dejaba entrever en un reportaje publicado en 1983: "Antena 3 contrató a profesionales considerados en punta, como José María García y otros, lo que hizo, entre otras cosas, que se dispararan sus gastos" (El País, 29-3-1983, p. 50). Luis Herrero cuenta que el "aterrizaje" de García no fue fácil y que "estuvo, de hecho, muy cerca de embarrancar por cuestiones económicas". La negociación estaba atascada por las cifras del contrato y él recuerda haber escuchado gritar a Martín Ferrand, desde una estancia contigua en la sede de la emisora en la calle Oquendo: "-iPues si García no acepta venir en esas condiciones, que se vaya!". Apunta también que, finalmente el desacuerdo no llegó a mayores porque Asensio le garantizó a García "la cantidad necesaria para que [...] colmara sus expectativas económicas con independencia de lo que figurara en el contrato de la radio" (Herrero, 2008: 157-158). El propio García ha confirmado en público la mediación de Asensio en aquellos momentos.

Otro tipo de rumores, estos concernientes a la nueva cadena Radio 80, tenían en cambio fundamento. Su situación económica la había puesto, ya a la altura de 1983, en situación de venta. Las declaraciones de su director, Luis Ángel de la Viuda, transmitían una cierta sensación de fracaso tras su primer año de funcionamiento: "Nos habíamos planteado una radio idealizada. Queríamos una radio de compañía, no de sobresaltos, para un público que no quiere agresiones" (El País, 29-3-1983, p. 50). Aunque en julio de 1983 anunciara una ampliación de capital de 150 a 650 millones de pesetas (La Vanguardia, 13-7-1983, p. 54), la realidad era bastante distinta, y de hecho las deudas se iban acumulando hasta el punto de plantearse su inviabilidad (Anuncios, no 170, 10 a 16-9-1984, p. 1). La ampliación, finalmente, no se llevó a cabo.

Desde un principio SER, COPE y Antena 3 aparecieron en la opinión pública como los máximos candidatos a comprarla (IP-Mark, no 239, enero 1984, p. 1). Junto con La Editorial Católica, que tenía un 10 por ciento, los principales accionistas de Radio 80 eran sociedades dependientes de los Bancos Central, Banesto, Bilbao, Vizcaya e Hispano Americano. Una nota de Antena 3, hecha pública a mediados de marzo de 1984, salía al paso del rumor de una posible ruptura en las negociaciones, si bien el director de programación, José Luis Orosa, dejó claro que la integración quedaba condicionada a que no amenazase "con colapsar el creciente desarrollo de que disfrutamos hasta ahora" (El País, 15-3-1984). Entretanto, en abril se firmó un acuerdo de cooperación entre ambas cadenas para emitir algunos programas simultáneamente. "No hay ninguna compra de acciones - dijo Luis Ángel de la Viudaporque no es una operación patrimonial", si bien Martín Ferrand lo calificó como "el primer paso de la fusión definitiva" (El País, 19-4-1984). 
Las ofertas de la COPE y la SER nunca llegaron a cuajar en pasos decididos. Una fuente interna de Radio 80 no identificada llegó a declarar: "Antena 3 necesita comprar Radio 80 pero no tiene el dinero; la SER tiene el dinero pero no nos necesita directamente, sino para evitar que la competencia se haga más fuerte con Radio 80" ("Discrepancias en la SER paralizan las negociaciones con Radio 80", Anuncios, no 171, 17-23-9-1984, p. 1). La de Antena 3 era la opción más lógica, porque a ambas les unía el modelo de ser cadenas basadas únicamente en emisoras de FM.

Así las cosas, a finales de 1984 los sucesos se fueron decantando hacia la firma del acuerdo definitivo entre Antena 3 y Radio 80. Luis Ángel de la Viuda admitía que, de entre las recibidas, la de Antena 3 era la mejor opción "por la edad de los personajes; que es muy importante en cualquier tipo de unión" (El País, 19-10-1984). Finalmente el 4 de diciembre se hizo pública la operación de compraventa de la totalidad de las acciones de Radio 80, "con el compromiso por parte de Antena 3 -informaba El Paísde pagar 126 millones de pesetas en efectivo y hacer frente a las deudas de Radio 80, unos 1.200 millones de pesetas, de los que Antena 3 pagará el $60 \%$ a través de publicidad y el $40 \%$ restante mediante créditos" (El País, 5-12-1984). Años más tarde, Martín Ferrand se referiría a Radio 80 como "un proyecto profesional magnífico", pero que tenía "una servidumbre muy grande": sus cinco bancos propietarios, "y esto es demasiado para cualquier empresa informativa" (Martín Ferrand, 1991: 27).

La Vanguardia, principal accionista de Antena 3, se hizo eco de la noticia en su primera página de tipografía, que luego era ampliada en el interior. Sus principales pronunciamientos se centraban en la significación de esta operación, tanto en el aspecto radiofónico como en el nunca olvidado televisivo, que fue el origen de todo:

Antena 3 de Radio comienza así su segunda etapa de expansión la cual, desde 68 emisoras, alcanzará inmediatamente unas 90 distribuidas por toda España, hasta completar la primera cobertura radiofónica española privada (...) La presente operación significa, igualmente, la aceleración de los trabajos conjuntos que ya venían realizándose, tendentes a la definición total de un proyecto de televisión netamente privada y comercial. Se remata así un proceso de transición que comenzó con el nacimiento, hace poco más de dos años, de Antena 3, una empresa radiofónica que desea subrayar siempre sus tres objetivos diferenciadores: privada, libre, independiente (La Vanguardia, 5-12-1984, p. 54).

Otro de los accionistas principales, $A B C$, calificó el acuerdo en sus páginas de hueco como "un hito en la historia de la radio privada en España" ( $A B C, 5-12-1984)$. Antena 3 alcanzaba con este acuerdo una cobertura prácticamente nacional. "Eso nos permitió cerrar más rápido de lo previsto el ciclo de Antena 3", reconoció años más tarde Martín Ferrand. "Con las emisoras que se nos duplicaban creamos lo que hoy funciona como Radio 80 Serie Oro, especializada en música de hace varios años, pero de gran calidad" (Martín Ferrand, 1991: 27). 


\section{Los elementos de una novedosa apuesta radiofónica}

El director general de Radio 80, Luis Ángel de la Viuda (1982: 27), escribió: "La aparición de 300 emisoras de frecuencia modulada supondrá una revolución en el mundo de la radio que alterará una situación que ha permanecido invariable desde hace tres décadas. Todas las emisoras se enfrentarán a una durísima competencia". Su empresa fue ciertamente protagonista, y también víctima como se ha visto, de esa nueva situación. Un reportaje de la época en El País señalaba al respecto como frase de apertura: "La experiencia de casi un mes de funcionamiento de nueve de las 120 emisoras privadas de frecuencia modulada está demostrando hasta ahora que una estación de FM no tiene por qué ser eminentemente musical" (El País, 27-5-1982).

El director de programación de Antena 3, José Luis Orosa, indicaba al autor del reportaje que "no nos hemos planteado hacer una radio con un lenguaje diferente al ya existente, y algún sector ya nos ha criticado por ello". Y añadía: "No nos gusta hacer diferencias entre onda media y frecuencia modulada". Reconocía que les tocaba "luchar contra la concepción que existe en este país de que la OM sirve para la transmisión de contenidos diversificados y la FM para los programas musicales", pero insistía en que la única diferencia entre ambas era la puramente técnica "que deriva de su cobertura más bien urbana y que presenta una mayor calidad" (El País, 27-5-1982).

Escribió años más tarde Martín Ferrand que "los sistemas técnicos de emisión no pueden conformar modos expresivos", y de ahí que "nosotros montamos una radio que pretendía ser, según decía el eslogan, 'la radio bien hecha”", con "un especial énfasis a los servicios informativos y a los programas con contenidos de actualidad" (Martín Ferrand, 1991: 29-30). Esa fue la gran apuesta de Antena 3: ofrecer programación convencional en cadena a través de emisoras de FM, hasta entonces prácticamente relegada al ámbito musical o de la experimentación, en vez de en OM. "Cuando nosotros empezamos - declaró Orosa avanzado 1983- la FM era una radio de segunda fila, que se utilizaba como cobertura auxiliar para apoyar la columna vertebral de la OM". Y concluía: "la barrera se ha roto, y tan es así que, por ejemplo, la política de la SER se encamina al refuerzo de las FM" (IP-Mark, no 236, octubre 1983, p. 47).

Cuando todavía no llegaba al año de vida, Martín Ferrand se atrevió a decir que "nuestra programación, que en principio fue calificada de visionaria, ha sido imitada por las grandes cadenas" (ABC, 19-2-1983, p. 87). De las innovaciones radiofónicas introducidas, destacaba Martín Ferrand que "las grandes cadenas estatales y privadas ya existentes han cambiado su programación para adecuarla a horarios que nosotros iniciamos hace diez meses" (El País, 17-2-1983). Lorenzo Díaz (1992: 440) resumió las claves del éxito radiofónico de la nueva cadena, aparte de "la valentía de llevar a la FM la programación convencional de la OM", en las siguientes: "la calidad del sonido FM- 
estéreo, fórmulas empresariales agresivas, la innovación en el lenguaje radiofónico y el esfuerzo profesional realizado".

El fichaje estrella en términos de audiencia y de publicidad fue el periodista José María García, con su programa Supergarcía en la medianoche. También formaron parte de la programación inicial otros conocidos periodistas -sin experiencia previa en el medio radiofónico- como Yale, Amilibia, José Antonio Plaza, Mayra Gómez Kemp y Carlos Pumares, entre otros, en una política que apenas había sido practicada hasta entonces por otras cadenas. Otros conocidos rostros televisivos, como Jesús Hermida y José Luis Balbín, se sumaron después. Su adaptación al mundo de la radio fue una de las claves del temprano éxito de Antena 3.

Según comentaba Orosa, "el resto son profesionales nuevos, la mayoría procedentes de otros medios y, por lo tanto, sin los tics tradicionales, lo cual ha proporcionado esa frescura y espontaneidad que a lo mejor se echa de menos en otras emisoras" (IPMark, no 236, 10-1983, p. 47). Martín Ferrand explicaba las bondades de esa mezcla entre "gente nueva con la fuerza de la juventud" y "los veteranos que conocen bien su oficio". "Así -razonaba- se produce el contagio de lo mejor de cada uno hacia los otros. Pero este tipo de renovación radiofónica es bastante inédito en el medio; nosotros creemos en ella" (La Vanguardia, 26-5-1983, p. 78).

La juventud de la plantilla de redactores y trabajadores, con una media de edad de entre 25 y 26 años, fue otra de las notas características de la cadena. Para más de un ochenta por ciento de ellos fue su primer puesto de trabajo (Martín Ferrand, 1991: 24). Algunos puestos de mayor responsabilidad recayeron sobre periodistas con experiencia profesional como José Cavero, director de los servicios informativos, Miguel Ángel Nieto y Miguel Ángel García Juez. En febrero de 1983 tenían doscientas personas en plantilla y otros tantos en calidad de "colaboradores artísticos" ( $A B C, 19-$ 2-1983, p. 87).

Este nuevo estilo empezó a marcar tendencia y era además reconocido así por buena parte de la opinión pública de la época. Al cumplirse un año del comienzo de sus emisiones, un medio rival como El País, que ese año lanzaba su propia emisora, reconocía que "desde su fundación ha sido la cadena de FM que más agresividad radiofónica y planteamientos competitivos ha demostrado" (El País, 27-5-1983). Además, las cifras de audiencia de las primeras oleadas del Estudio General de Medios resultaron alentadoras. En el acumulado entre mayo de 1982 y mayo de 1983, es decir, su primer año de emisiones, contaba ya con 752.000 oyentes, de los que la mitad se encontraban entre los 19 y 34 años. En el segmento horario desde la medianoche hasta las 7 de la mañana era la cadena líder gracias al tirón de José María García (Anuncios, no 180, 14 a 20-11-1983, pp. 11 y 14). 
Cuando se anunció la compra de Radio 80 por Antena 3, el semanario publicitario Anuncios dedicó un editorial a la importante noticia. En él calificaba de "encomiable el esfuerzo llevado a cabo por quienes, como Antena 3, han salido de la nada -aunque cuenten con el concurso de prestigiosos profesionales del medio- para superar la nada despreciable cifra del millón de oyentes" ("Antena 3 y el mapa radiofónico español", Anuncios, no 147, 27-2 a 4-3-1984). La última oleada del EGM, correspondiente a octubre y noviembre de 1983 , había dado 1.070 .000 oyentes a Antena 3, mientras que Radio 80 contaba con apenas 233.000.

Otra de las claves que incidieron positivamente en la credibilidad de la nueva cadena fue la línea informativa independiente: a la sazón, una de sus principales señas de identidad corporativa. Martín Ferrand declaró, ya desde los comienzos, que Antena 3 había "aportado al panorama radiofónico español pluralidad e independencia informativa" (El País, 17-2-1983). Esta idea fue utilizada profusamente como reclamo en la publicidad de la cadena que aparecía en los periódicos y leitmotiv constante en su autodefinición.

\section{Conclusiones}

Los socios que impulsaron y conformaron Antena 3, empresas periodísticas en mayor parte, se unieron para hacer televisión privada, como también hicieron otras iniciativas periodísticas y radiofónicas del momento. En esa tarea fueron los que mayor empeño pusieron tanto desde el punto de vista empresarial como profesional-periodístico. Frente a la mayor pasividad de otros grupos, su empuje les llevó a organizar campañas de opinión pública en pro de ella, e incluso acudieron al Tribunal Constitucional para intentar forzar una sentencia favorable a sus intereses, que finalmente no llegó.

Entretanto la apertura de la radio al sector privado hizo virar los intereses de todos esos grupos, y también de Antena 3, a esta nueva puerta que se abría para la expansión de sus empresas, en espera de tiempos mejores para el negocio televisivo. Como escribió Balsebre (2002: 483), con la excepción de Nicolás María de Urgoiti en los años veinte del pasado siglo, "nunca anteriormente a 1980-1982 los grupos económicos que sostienen empresas editoras de prensa se habían preocupado por invertir en la radiodifusión española". También en este nuevo sector, Antena 3 tomó la delantera en cuanto a estrategia de expansión empresarial e innovación en la programación: una forma distinta de hacer radio que acabó arrastrando a las demás cadenas. En este sentido, la apuesta de Antena 3 por una programación generalista a través de la FM fue la principal novedad, que acabaría además por imponerse a los pocos años hasta hacer casi irrelevante la distinción entre la FM y la OM. 
La joven cadena irrumpió con fuerza en el panorama radiofónico español de los años ochenta, con un estilo nuevo, joven y desenfadado, si bien basado inicialmente en la seguridad que le podían dar periodistas conocidos, aunque algunos de ellos vinieron de medios distintos al radiofónico. Aunque nació para hacer televisión, "esto no quiere decir que no nos tomemos en serio la radio" (El País, 29-3-1983), como dijo su director general Manuel Martín Ferrand cuando Antena 3 Radio aún no había cumplido un año de vida.

En definitiva, Antena 3 fue una empresa periodística singular por varias razones. En primer lugar, su ya referida acta de nacimiento para la televisión, a la que nunca renunció. En segundo lugar, la composición plural de su accionariado, que englobó a más de una veintena de empresas periodísticas, fenómeno infrecuente en la historia de los medios españoles de comunicación. El "desembarco de la prensa en el control de la radio en España" en los años ochenta, al que acertadamente alude Balsebre, tiene en Antena 3 un claro ejemplo; también en la consecuencia que él advierte de que "este nuevo perfil de la propiedad de la radio española intervendrá [...] activamente en la consolidación del prestigio político de la radio" (Balsebre, 2002: 483).

También en el plano de la propiedad, y a la luz de lo ocurrido, el papel de los hermanos Jiménez de Parga tuvo un doble componente jurídico y político: jurídico porque los conocimientos de ambos en materias de derecho político y mercantil resultaban sumamente útiles para el primer desarrollo de la cadena y para su aspiración a obtener finalmente un canal privado de televisión; y político por su clara significación en la vida pública española en los aledaños de los gobiernos de UCD.

A pesar de la pluralidad de sus socios capitalistas, es cierto que desde su fundación las posiciones predominantes del grupo Godó en su capital hicieron de éste su cara más visible, aunque se delegó la gestión ejecutiva, tanto comercial como periodística, en el director general Manuel Martín Ferrand, auténtica alma del proyecto. En todo caso, Antena 3 pudo hacer honor a su eslogan, "La primera cadena de radio totalmente privada en España", que le ayudó a posicionarse públicamente y ser reconocida como empresa políticamente independiente. Tuvo conexiones indirectas, vía capital, con la UCD gobernante pero el crecimiento y éxito de la cadena se debieron más a la gestión e iniciativas del equipo directivo que a las concesiones -escasas- recibidas de los gobiernos centristas en 1981 y 1982, o a la hipotética influencia de un sector minoritario, al fin y al cabo, de accionistas cercanos al gobierno.

Finalmente, su singularidad radicó también en haber hecho calar en la opinión pública de su tiempo la identificación de Antena 3 con la libertad y la independencia. Enarbolando la bandera de la libertad, se erigió conscientemente en estandarte de dicha causa en la televisión y en la radio gracias a una eficaz labor de marketing. Cuando ni siquiera se habían conseguido las primeras licencias de radio, Antena 3 ya proclamaba en su publicidad: "Un país no puede plantearse su futuro con una sola 
televisión. De la misma manera que existe más de un periódico, más de una emisora de radio, debe existir más de una sola opción de televisión. Por eso ha nacido Antena 3" (La Vanguardia, 15-11-1981, p. 21). Eran conceptos y razonamientos sencillos que, utilizados para la televisión, sirvieron de refuerzo para la imagen de la cadena de radio que echó a andar en 1982 hasta que la televisión privada fuera posible.

\section{Referencias bibliográficas}

ANTENA 3 (1982): Las razones de la televisión privada, Madrid, Gráficas Valencia.

BALSEBRE, A. (2002): Historia de la radio en España. Vol. II (1939-1985), Madrid, Cátedra.

BARRERA, C. (1995): Sin mordaza. Veinte años de prensa en democracia, Madrid, Temas de Hoy.

BEAUMONT, J.F. (1982): “De las emisoras FM a las empresas 'multimedios'”, en AEDE, no 6, pp. 56-61.

BUSTAMANTE, E. (2013): Historia de la Radio y la Televisión en España. Una asignatura pendiente de la democracia, Barcelona, Gedisa.

DE LA VIUDA, L.A. (1982): "La empresa de la radiodifusión", en AEDE, no 6, pp. 17-27.

DÍAZ, L. (1992): La radio en España, 1923-1993, Madrid, Alianza.

FAUS BELAU, A. (2007): La radio en España (1896-1977), Madrid, Taurus.

FERNÁNDEZ, I. y SANTANA, F. (2000): Estado y medios de comunicación en España, Madrid, Alianza.

FRANQUET, R. (1988): "Radio: un oligopolio en transformación", en BUSTAMANTE, E. y ZALLO, R. (editores): Las industrias culturales en España, Madrid, Akal, pp. 77107.

FRANQUET, R. y MARTÍ, J.M. (eds.) (1989): 10 años de libertad de información en la radio española, 1977-1987. Barcelona, Departament de Comunicació Audiovisual i Publicitat. 
GARCÍA LLOVET, E. (1991): El régimen jurídico de la radiodifusión. Madrid, Marcial Pons.

GONZÁLEZ NAVARRO, F. (1982): Televisión pública y televisión privada, Madrid, Civitas. HERRERO, L. (2007): Los que le llamábamos Adolfo, Madrid, La Esfera de los Libros. -(2008): En vida de Antonio Herrero, Madrid, La Esfera de los Libros.

JIMÉNEZ DE PARGA, M. (2008): Vivir es arriesgarse, Barcelona, Planeta.

JIMÉNEZ DE PARGA, R. (1982): "La iniciativa privada en los medios audiovisuales", en $A E D E, \mathrm{n}$ - 6, pp. 13-15.

MARTÍN FERRAND, M. (1991): "Presente y futuro de Antena 3", en FAUS, A.: Radio y Universidad, Pamplona, Servicio de Publicaciones de la Universidad de Navarra, pp. 21-45.

MIRÓ, S. (1997): Zeta, el imperio del zorro, Madrid, Vosa.

NOGUÉ, A. y BARRERA, C. (2006): La Vanguardia, del franquismo a la democracia, Madrid, Fragua.

PALACIO, M. (2012): La televisión durante la Transición española, Madrid, Cátedra.

\section{Fuentes hemerográficas}

Prensa diaria: $A B C, E$ E País, La Vanguardia.

Prensa especializada: IP-Mark, Anuncios.

\section{Fuentes orales}

DE LA VIUDA, Luis Ángel (15-4-2015)

GONZÁLEZ DE HARO, Rosalía (17-6-2015) 